Research Paper

\title{
Clinical Factors Aifecting the Direct Cost of Patients Hospitalized with Acute Exacerbation of Chronic Obstructive Pulmonary Disease
}

\author{
Tacettin Örnek $^{\bowtie}$, Meltem Tor, Remzi Altın, Figen Atalay, Elif Geredeli, Ömer Soylu, Fatma Erboy \\ Department of Chest Diseases, Faculty of Medicine, Zonguldak Karaelmas University, Zonguldak, Turkey.
}

$\triangle$ Corresponding author: Dr. Tacettin ÖRNEK, Department of Chest Diseases, Faculty of Medicine, Zonguldak Karaelmas University, 67600, Zonguldak, TURKEY. Tel: +90.536.3387324 Fax: +90.372.2610155 E-mail: tacettin.ornek@karalemas.edu.tr

(C) Ivyspring International Publisher. This is an open-access article distributed under the terms of the Creative Commons License (http://creativecommons.org/ licenses/by-nc-nd/3.0/). Reproduction is permitted for personal, noncommercial use, provided that the article is in whole, unmodified, and properly cited.

Received: 2012.01.02; Accepted: 2012.05.29; Published: 2012.06.05

\begin{abstract}
Background: Chronic obstructive pulmonary disease (COPD) is a disease of increasing significance in terms of economic and social burden due to its increasing prevalence and high costs. Direct costs of COPD are mostly associated with hospitalization expenditures. In this study, our objective was to investigate the costs of hospitalization and factors affecting these costs in patients hospitalized due to acute exacerbation of COPD (AECOPD).

Methods: A total of 284 patients hospitalized AECOPD were included in the study. Data were examined retrospectively using the electronic hospital charts.

Results: Mean duration of hospitalization was II $.38 \pm 6.94$ days among study patients. Rates of admission to the intensive care unit, initiation of non-invasive mechanical ventilation (NIMV) and invasive mechanical ventilation (MIV) were $37.3 \%(n=106), 44.4 \%(n=126)$ and $18.3 \%(n=52)$ respectively. The rate of mortality was $14.8 \%(n=42)$. Mean cost of a single patient hospitalized for an AECOPD was calculated as $\$ 1765 \pm 2139$. Mean cost of admission was $\$ 889 \pm 533$ in standard ward, and $\$ 2508 \pm 2857$ in intensive care unit (ICU). The duration of hospitalization, a FEVI\% predicted value below 30\%, having smoked 40 package-years or more, the number of co-morbidities, NIMV, IMV, ICU, exitus and the number of hospitalizations in the past year were among the factors that increased costs significantly. Hospital acquired pneumonia, chronic renal failure and anemia also increased the costs of COPD significantly.

Conclusion: The costs of treatment increase with the severity of COPD or with progression to a higher stage. Efforts and expenditures aimed at preventing COPD exacerbations might decrease the costs in COPD.
\end{abstract}

Key words: acute exacerbation, co-morbidity, COPD, cost, economics, hospitalization.

\section{Introduction}

Chronic obstructive pulmonary disease (COPD) is one of the most important causes of morbidity and mortality overall the world. The prevalence of COPD is expected to increase rapidly in the near future due to the persistence of risk factors of COPD and changes in the age characteristics of the world population. COPD was the most common 6th cause of death worldwide in 1990; however it is assumed to range the 3rd in 2020 [1].

Individuals with COPD typically experience acute exacerbations, which may result in hospitalization. Acute exacerbation of COPD (AECOPD) is defined as "an acute worsening in the patient's condition from the stable state, which is sustained and may 
warrant the patient to seek additional treatment" [2].

COPD is a disease that brings significant economic and social burden due to its both direct and indirect costs [3]. Direct costs include drug expenditures, diagnostic expenditures, expenditures associated with disease follow-up, out-patients clinic, emergency ward, and hospitalizations [4-8]. It has been reported that the direct cost of COPD has been $\$ 29.5$ billion whereas total cost has been $\$ 49.9$ billion in the year 2002 in the United States of America (USA) [8]. In the European Union, the total direct costs of respiratory disease are estimated to be about $6 \%$ of the total healthcare expenditures, with COPD accounting for $56 \%$ (38.6 billion Euros) of this cost of respiratory disease [9].

In this study, our objective was to examine the costs of hospitalization and factors affecting these costs in patients referring to the clinic of chest diseases and hospitalized due to AECOPD.

\section{Methods}

\section{Patients}

All patients hospitalized primarily due to AECOPD at the Department of Chest Diseases of Zonguldak Karaelmas University Medical School between the dates September 2010 and August 2011 were included in the study. The Ethic Committee of our institution approved the study protocol. The diagnosis of COPD was established by the GOLD criteria [3] in our hospital. Patients presenting with clinical symptoms suggestive of COPD and FEV1/FVC $<70 \%$ in spirometric examination were diagnosed with COPD. The diagnosis was established by the clinical findings in the presence of risk factors for COPD in patients who could not comply with the spirometric examination. Demographic features, clinical data and hospitalization bills of a total of 284 hospitalization files were screened retrospectively using the electronic hospital charts. Bills were evaluated in two categories as ward bills and intensive care unit (ICU) bills. Ward bills were examined in four categories consisting of laboratory, disbursement, drug and clinical (diagnostic procedures, interventions and oxygen therapy) procedures. Since the study was performed in a university hospital, prices of all expenditures were determined by the state. Expenditures associated with the ICU were not sub-divided into categories, since these expenditures determined by the state were at fixed prices according to disease severity and number of days of hospitalization. Expenditures were calculated in US dollars (exchange rate at the time of the study was 1.89 Turkish liras per US dollars, 0.76 Euro per US dollars).

\section{Statistical analysis}

Statistical analysis was performed using the Statistical Package for Social Sciences 11.0 (SPSS Inc., Chicago, IL, USA) software. Continuous variables were summarized as means $( \pm S D)$. Variables between two groups were compared with an unpaired Student's $t$ test. Distribution of categorical groups was examined with the Kolmogorov Smirnov test. Mann Whitney $U$ test was used to study the difference between variables when normal distribution did not exist in at least one of the groups. All values were two-sided. A P value less than 0.05 was considered statistically significant.

\section{Results}

The 284 hospitalization files included in the study belonged to a total of 242 patients due to recurrent hospitalizations within one year. We evaluated the demographic features of study population (Table 1). This study population is unique since the most of the patients were coal miners $(44.1 \%)$. Additionally, study patients were quite old (mean age $70.35 \pm 10.65)$ and male dominant, as we expected. Demographic characteristics of study sample were summarized in Table 1. History of one or more than one hospitalizations in the past year was present in $71.1 \% \quad(n=101)$ of the patients. Mean amount of smoking was $42.69 \pm 22.91$ (4-140) package-years in patients with history of smoking. Evaluation of the clinical data demonstrated that non-invasive mechanical ventilation (NIMV) had been administered in almost half of the patients (Table 2).

Mean cost of a single patient hospitalized in the department of chest diseases due to AECOPD has been determined as $\$ 1765 \pm 2139$. The majority of this figure consisted of medications and clinical procedures in standard ward patients (Table 3).

Factors that increased costs significantly included the number of hospitalizations, prolonged periods of hospitalization, having co-morbidities, a FEV1\% predicted value lower than $30 \%$, smoking 40 package-years or more, having NIMV, having invasive mechanical ventilation (IMV), hospitalization in the ICU and exitus (Table 4). Among the co-morbidities hospital acquired pneumonia, chronic renal failure and anemia increased the costs of COPD significantly (Table 5). There was no significant difference in clinical costs, laboratory costs and costs of consumables when compared between patients with and without hospital acquired pneumonia (HAP). Cost of medications was $\$ 391 \pm 339 \$$ in patients with $\operatorname{HAP}(n=60)$, and $\$ 202 \pm 129$ in patients without HAP $(\mathrm{n}=205)(\mathrm{p}<0.001)$. 
Table I. Demographic characteristics of study patients.

\begin{tabular}{ll}
\hline $\begin{array}{l}\text { Gender - no (\%) } \\
\text { Male }\end{array}$ & $168(69.4)$ \\
Female & $74(30.6)$ \\
Age - year & $70.35 \pm 10.65$ \\
Mean & $34-90$ \\
Range & \\
Occupation - no (\%) & $105(44.1)$ \\
Coal miner & $71(29.8)$ \\
Housewife & $23(9.7)$ \\
Workman & $8(3.4)$ \\
Officer & $31(13.0)$ \\
Other & \\
Smoking - no (\%) & $20(8.4)$ \\
Current smoker & $128(54.0)$ \\
Ex-smoker & $89(37.6)$ \\
Non-smoker & \\
\hline
\end{tabular}

Table 2. Clinical features of study patients.

\begin{tabular}{ll}
\hline $\begin{array}{l}\text { Intensive care unit patient- } \mathbf{n} / \mathbf{n} \text { total (\%) } \\
\text { Mechanical ventilation }\end{array}$ & $106 / 284(37.3)$ \\
Patient receiving NIMV - n/n total (\%) & $126 / 284(44.4)$ \\
$\begin{array}{l}\text { Patient receiving IMV - n/n total (\%) } \\
\text { Mean duration of hospitalization- days }\end{array}$ & $52 / 284(18.3)$ \\
(min-max.) & $11.38 \pm 6.94(1-49)$ \\
$\begin{array}{l}\text { Mean duration of hospitalization in ICU- days } \\
\text { (min-max.) }\end{array}$ & $7.19 \pm 7.05(1-43)$ \\
$\begin{array}{l}\text { Mean duration of hospitalization in standard } \\
\text { ward- days (min- max) }\end{array}$ & $9.32 \pm 5.17(1-36)$ \\
Mean FEV1\% predicted value- (n) & $43.86 \pm 17.04(135)$ \\
Mortality- $\mathbf{n} / \mathbf{n}$ total (\%) & $42 / 284(14.8)$ \\
\hline
\end{tabular}

Table 3. Mean cost of patients hospitalized for AECOPD

\begin{tabular}{llll}
\hline Unit of admission & Cost- $\$$ & \multicolumn{2}{l}{ Daily cost- $\mathbf{~ n}$} \\
\hline Mean cost in standard ward & $889 \pm 533$ & $98 \pm 37$ & 265 \\
$\quad$ Laboratory & $167 \pm 140$ & & \\
$\quad$ Consumables & $56 \pm 73$ & & \\
$\quad$ Drugs & $245 \pm 212$ & & \\
$\quad$ Clinical & $422 \pm 262$ & & 106 \\
$\begin{array}{l}\text { Mean cost of intensive care } \\
\text { unit }\end{array}$ & $2508 \pm 2857$ & $330 \pm 181$ & \\
Total mean cost & $1765 \pm 2139$ & $147 \pm 118$ & 284 \\
\hline
\end{tabular}

Table 4. Factors associated with hospitalization costs in patients with AECOPD.

\begin{tabular}{|c|c|c|c|}
\hline \multirow[t]{2}{*}{ Parameter } & \multicolumn{2}{|l|}{ Cost- $\$$} & \multirow[b]{2}{*}{$\mathrm{p}$} \\
\hline & present & absent & \\
\hline $\begin{array}{l}\text { Number of hospitali- } \\
\text { zations* }>1 \text { - (n) }\end{array}$ & $2082 \pm 2852(69)$ & $1126 \pm 1068(98)$ & 0.003 \\
\hline $\begin{array}{l}\text { Number of hospitali- } \\
\text { zations* }>2-(\mathrm{n})\end{array}$ & $2181 \pm 3104(43)$ & $1292 \pm 1484(124)$ & 0.014 \\
\hline $\begin{array}{l}\text { Hospitalization longer } \\
\text { than } 7 \text { days- (n) }\end{array}$ & $2193 \pm 2384(198)$ & $782 \pm 805(86)$ & $<0.001$ \\
\hline $\begin{array}{l}\text { FEV1\% predicted value } \\
\text { below } 50 \%-(\mathrm{n})\end{array}$ & $1007 \pm 1003$ & $1240 \pm 969(48)$ & 0.189 \\
\hline $\begin{array}{l}\text { FEV1\% predicted value } \\
\text { below } 30 \%-(\mathrm{n})\end{array}$ & $1467 \pm 1012$ & $1057 \pm 958(102)$ & 0.037 \\
\hline History of smoking- (n) & $1895 \pm 2342(174)$ & $1487 \pm 1652(105)$ & 0.090 \\
\hline $\begin{array}{l}\text { Smoking } 40 \text { pack- } \\
\text { age-years or more- (n) }\end{array}$ & $2266 \pm 2858(101)$ & $1383 \pm 1186(71)$ & 0.015 \\
\hline $\begin{array}{l}\text { Presence of } \\
\text { co-morbidities- (n) }\end{array}$ & $1834 \pm 2191(266)$ & $748 \pm 372(18)$ & 0.001 \\
\hline $\begin{array}{l}\text { Presence of more than } \\
\text { one comorbidities- }(n)\end{array}$ & $2041 \pm 2434(190)$ & $1209 \pm 1189(94)$ & $<0.001$ \\
\hline $\begin{array}{l}\text { Admission to intensive } \\
\text { care unit- (n) }\end{array}$ & $3217 \pm 2914(106)$ & $901 \pm 512(178)$ & $<0.001$ \\
\hline NIMV- (n) & $2185 \pm 1848(126)$ & $1431 \pm 2296(158)$ & 0.002 \\
\hline IMV- (n) & $4415 \pm 3465(52)$ & $1172 \pm 1010(232)$ & $<0.001$ \\
\hline Exitus- (n) & $4033 \pm 3510(42)$ & $1372 \pm 1492(242)$ & $<0.001$ \\
\hline
\end{tabular}

*Number of hospitalizations due to acute exacerbation of COPD in the past one year

Table 5. Co-morbidities associated with hospitalization costs in patients with AECOPD.

\begin{tabular}{|c|c|c|c|}
\hline & \multicolumn{2}{|c|}{ Cost- $\$$} & \multirow[b]{2}{*}{$p$} \\
\hline & present & absent & \\
\hline Hypertension- (n) & $1627 \pm 1696(n=122)$ & $1870 \pm 2419(\mathrm{n}=162)$ & 0.321 \\
\hline $\begin{array}{l}\text { Communi- } \\
\text { ty-acquired pneu- } \\
\text { monia- (n) }\end{array}$ & $1907 \pm 1931(\mathrm{n}=115)$ & $1669 \pm 2270(n=169)$ & 0.358 \\
\hline $\begin{array}{l}\text { Congestive heart } \\
\text { failure- }(\mathrm{n})\end{array}$ & $3597 \pm 4591(\mathrm{n}=74)$ & $3246 \pm 3829(n=211)$ & 0.557 \\
\hline $\begin{array}{l}\text { Hospital-acquired } \\
\text { pneumonia - (n) }\end{array}$ & $3293 \pm 3358(n=70)$ & $1266 \pm 1187(n=214)$ & $<0.001$ \\
\hline $\begin{array}{l}\text { Diabetes mellitus- } \\
\text { (n) }\end{array}$ & $1555 \pm 1754(\mathrm{n}=64)$ & $1827 \pm 2238(\mathrm{n}=220)$ & 0.371 \\
\hline $\begin{array}{l}\text { Pneumoconiosis- } \\
\text { (n) }\end{array}$ & $1813 \pm 2365(n=49)$ & $1756 \pm 2094(\mathrm{n}=235)$ & 0.864 \\
\hline $\begin{array}{l}\text { Pulmonary embo- } \\
\text { lism- (n) }\end{array}$ & $1743 \pm 1883(n=35)$ & $1769 \pm 2176(n=249)$ & 0.946 \\
\hline $\begin{array}{l}\text { Coronary artery } \\
\text { disease- }(n)\end{array}$ & $1449 \pm 1381(n=25)$ & $1796 \pm 2198(n=259)$ & 0.522 \\
\hline $\begin{array}{l}\text { Sleep apnea syn- } \\
\text { drome- (n) }\end{array}$ & $1575 \pm 1341(n=18)$ & $1778 \pm 2183(n=266)$ & 0.785 \\
\hline $\begin{array}{l}\text { Chronic renal fail- } \\
\text { ure - (n) }\end{array}$ & $2280 \pm 1697(\mathrm{n}=17)$ & $1733 \pm 2162(\mathrm{n}=267)$ & 0.026 \\
\hline Malignancy- (n) & $2436 \pm 2313(\mathrm{n}=16)$ & $1726 \pm 2126(n=268)$ & 0.073 \\
\hline Anemia- (n) & $3896 \pm 3393(n=13)$ & $1663 \pm 2014(\mathrm{n}=271)$ & 0.002 \\
\hline
\end{tabular}




\section{Discussion}

Several studies have been performed about the cost of COPD; however there are few studies investigating the factors affecting this cost. In our study, we determined that the mean cost of a patient admitted to the clinic of chest diseases (standard ward and/or respiratory intensive care unit) is $\$ 1765 \pm 2139$. Study results have demonstrated that the number and duration of hospitalization, FEV1 values, smoking, mechanical ventilation, hospitalization in the ICU, exitus and co-morbidities affected the cost of COPD significantly.

Direct cost of COPD was 18 billion Dollars in the year 2002 in USA; whereas this figure has increased up to 29.5 billion Dollars in the year 2010. Most of the direct cost has been reported to consist of hospital expenses [8]. One study performed in the USA has separated hospitalized patients according to the presence or absence of COPD; and costs were 2.4 times higher in patients with COPD $(n=42,472)$ compared to those without COPD $(n=1,221,615)[10]$.

Costs of patients hospitalized for COPD varies greatly by the countries. One study performed in Singapore has determined that the mean cost of a COPD patient hospitalized in the standard ward within a period of 5 years was $\$ 7184$ [11]. Mean cost of COPD has been calculated as $\$ 2008$ in a cost-analysis study performed by Dalal et al. in the USA on 37089 patients with COPD [12]. Cost has been reported as \$305 in out-patients, \$327 in emergency ward patients, $\$ 9745$ in standard ward patients and $\$ 33440$ in intensive care unit patients. In the study of Ozkaya et al. performed in Turkey, mean duration has been found as $\$ 718 \pm 364$ per admission among patients hospitalized for AECOPD [13]. However, costs of patients admitted due to AECOPD are expected to be greater since ICU patients who constitute the majority of costs have not been included. Another study from Turkey has demonstrated that patients with AECOPD were responsible from the great majority of total costs of patients admitted to the clinic of chest diseases and that mean cost was \$997[14]. The rates of COPD costs figured out in our study are quite lower compared to those of the other countries.

A retrospective study performed on a total of 413 COPD patients has grouped patients by the results of spirometric examination, and reported that the hospital costs were $\$ 680, \$ 2658$ and $\$ 6770$ in patients with mild, moderate and severe COPD, respectively [15]. Although most of the patients who could not perform spirometry or cooperate during spirometry and thus had missing spirometric values were very severe COPD patients that required admission to intensive care unit; costs were significantly higher in patients with a FEV1\% predicted value lower than $30 \%$. This has suggested a strong relationship between spirometric values and costs of COPD.

A multi-centered study performed in China has evaluated the data of 439 patients hospitalized for AECOPD retrospectively and noted that age $(p<0.01)$ and days of hospitalization $(p<0.01)$ correlated positively with the costs of COPD. A total of 321 patients have been further examined and it has been reported that NIMV $(p<0.01), M V(p<0.01)$ and admission to ICU $(p<0.01)$ increased the cost of COPD significantly [16]. Results of this Chinese study on the factors affecting costs of COPD resemble the results of our study; however contrary to our results, no significant differences has been determined between the costs of patients with history of more than two hospitalizations in the past year and patients with history of two or less hospitalizations. In the light of these data and the data of our study, we suggest that decreasing the costs of ICU should have a very important role in decreasing the costs of COPD, although the number of patients hospitalized in the ICU is lower.

COPD is often a disease of prolonged smokers and therefore might accompany several diseases associated with smoking or aging [17]. COPD itself might also lead to co-morbid conditions via systemic effects [18]. The risks of cardiovascular diseases, diabetes, anemia, pulmonary embolism [19] and respiratory infections [20] are increased in patients with COPD. It has been determined that the risk of death due to AECOPD is strongly related with the presence of significant co-morbidities and need for ventilator support [21]. In AECOPD requiring hospitalization, chronic renal failure predicts in-hospital mortality, post-discharge mortality or both, independently [22]. A prevalence of $23.1 \%$ has been determined in a population of 312 hospitalized COPD patients [23]. A prospective study performed on patients with COPD has reported that anemia is a risk factor for dyspnea, dysfunctional capacity and mortality [24]. Pneumonia is an important part of COPD burden [25]. In their study, Chen YH et al. have demonstrated that hypertension and cor pulmonale increased the cost of COPD significantly, and did not affect the cost of renal failure in patients hospitalized for AECOPD [16]. Although chronic renal failure, anemia and HAP were determined as the factors increasing the costs in our study, Chen $\mathrm{YH}$ et al. have not examined the effects of anemia and pneumonia. Similarly, mean duration of hospitalization was 20.7 days in the same study; the rate of patients admitted to the ICU was $14.3 \%$, the rate of NIMV was $21.8 \%$, IMV was $9.3 \%$ and mortality rate was $7.2 \%$. Hence a distribution pattern which was 
quite different compared to the distribution features of our study was presented. We concluded that the contradictory results obtained in the two studies stemmed from these differences in patient distribution profiles.

Smoking is the most important cause of COPD. The high number of non-smokers among COPD patients was a significant finding in our study. This might be partially explained by the presence of risk factors other than smoking (exposure to biomass, being a coal heaver) in our patient population. Non-smoker COPD patients included in our study consisted of coal miners in $20 \%$ and housewives in $62 \%$. Exposure to biomass has been determined to be at quite high rates among housewives in our country [26]. The mortality of COPD has been reported to be associated with smoking in $85 \%$ in males and $70 \%$ in females [27]. Several population studies have demonstrated that quitting smoking allowed the annual rate of reduction in FEV1 to regress to the rate noted in never smokers [28]. Relationship between tobacco smoke and COPD total cost is very clear [29,30]. In our study, we determined that the costs of COPD were greater among patients who had smoked more. We believe the fight against smoking will not only decrease the costs of patients admitted for AECOPD, but also prevent emergence and development of COPD and thus decrease the total cost of COPD burden.

All these studies suggest that the costs increase with the increasing severity of COPD (ICU, NIMV, IMV etc.) or with progression to the next stage. Currently, the prevalence of COPD is increasing rapidly, although the prevalence of several other diseases has decreased [31]. Although the cost and prevalence of COPD, which is a preventable disease, is quite high, studies aimed at investigating the cost of COPD and the factors influencing this cost are quite inadequate. Efforts and expenditures aimed at preventing further worsening of COPD might decrease the cost of COPD at any stage. In this study, we suggest that future costly measures of governments aimed at preventing the emergence or progression of COPD might be "cost-effective".

\section{Competing Interests}

The authors have declared that no competing interest exists.

\section{References}

1. Lopez AD, Shibuya $K$, Rao $C$, et al. Chronic obstructive pulmonary disease: current burden and future projections. Eur Respir J. 2006; 27: 397-412.

2. Burge S, Wedzicha JA. COPD exacerbations: Definitions and classifications. Eur Respir J 2003; 41 (Suppl): S46-S53.
3. [Internet] Global Strategy for the Diagnosis, Management and Prevention of COPD. Global Initiative for Chronic Obstructive Lung Disease (GOLD) 2010. http:/ / www.goldcopd.org.

4. Sullivan SD, Ramsey SD, Lee TA. The economic burden of COPD. Chest. 2000; 117 (Suppl 2): S5-S9.

5. Wouters EF. Economic analysis of the Confronting COPD survey: An overview of results. Respir Med. 2003; 97 (Suppl C): S3-S14.

6. Jansson SA, Andersson F, Borg S, et al. Costs of COPD in Sweden according to disease severity. Chest. 2002; 122: 1994-2002.

7. Andersson F, Borg S, Jansson SA, et al. The costs of exacerbations in chronic obstructive pulmonary disease (COPD). Respir Med. 2002; 96: 700-8.

8. [Internet] National Heart Lung and Blood Institute. Morbidity and mortality chartbook on cardiovascular, lung and blood diseases. http://www.nhlbi.nih.gov/resources/docs/2009_ChartBook.pdf

9. [No authors listed] European Respiratory Society. European lung white book. Huddersfield, UK: European Respiratory Society Journals; 2003.

10. Grasso ME, Weller WE, Shaffer TJ, et al. Capitation, managed care, and chronic obstructive pulmonary disease. Am J Respir Crit Care Med. 1998; 158: 133-8.

11. Teo WS, Tan WS, Chong WF, et al. Economic burden of chronic obstructive pulmonary disease. Respirology. 2012; 17: 120-6.

12. Dalal AA, Christensen L, Liu F, et al. Direct costs of chronic obstructive pulmonary disease among managed care patients. Int J Chron Obstruct Pulmon Dis. 2010; 5: 341-9.

13. Ozkaya S, Findik S, Atici AG. The costs of hospitalization in patients with acute exacerbation of chronic obstructive pulmonary disease. Clinicoecon Outcomes Res. 2011; 3: 15-8.

14. Hacievliyagil SS, Mutlu LC, Gülbaş G, et al. Comparison of the costs of the patients hospitalized to the pulmonary disease department. Turkish Thoracic Journal. 2006; 7: 11-6

15. Hilleman DE, Dewan N, Malesker M, et al. Pharmacoeconomic evaluation of COPD. Chest. 2000; 118: 1276-85.

16. Chen $\mathrm{YH}, \mathrm{Yao} \mathrm{WZ}$, Cai BQ, et al. Economic analysis in admitted patients with acute exacerbation of chronic obstructive pulmonary disease. Chin Med J. 2008; 121: 587-91.

17. Soriano JB, Visick GT, Muellerova H, et al. Patterns of comorbidities in newly diagnosed COPD and asthma in primary care. Chest. 2005; 128: 2099-107.

18. Agustí AG. Systemic effects of chronic obstructive pulmonary disease. Proc Am Thorac Soc. 2005; 2: 367-70.

19. Van der Molen T. Co-morbidities of COPD in primary care: frequency, relation to COPD, and treatment consequences. Prim Care Respir J. 2010; 19: 326-34.

20. Sethi S. Infection as a comorbidity of COPD. Eur Respir J. 2010; 35: 1209-15.

21. Connors AF Jr, Dawson NV, Thomas C, et al. Outcomes following acute exacerbation of severe chronic obstructive lung disease. The SUPPORT investigators (Study to Understand Prognoses and Preferences for Outcomes and Risks of Treatments). Am J Respir Crit Care Med. 1996; 154 (4 Pt 1): 959-67.

22. Antonelli Incalzi R, Fuso L, De Rosa M, et al. Co-morbidity contributes to predict mortality of patients with chronic obstructive pulmonary disease. Eur Respir J. 1997; 10: 2794-800.

23. John M, Lange A, Hoernig S, et al. Prevalence of anaemia in chronic obstructive pulmonary disease: comparison to other chronic diseases. Int J Cardiol 2006; 111: 365-70.

24. Cote C, Zilberberg MD, Mody SH, et al. Haemoglobin level and its clinical impact in a cohort of patients with COPD. Eur Respir J. 2007; 29: 923-9.

25. Bekçi T, Kurtipek E, Kesli R, et al. The effect of telithromycin on inflammatory markers in chronic obstructive pulmonary diseases. Eur J Gen Med. 2009; 6: 218-22.

26. Kiraz K, Kart L, Demir R, et al. Chronic pulmonary disease in rural women exposed to biomass fumes. Clin Invest Med. 2003; 26: 243-8

27. [No authors listed] American Thoracic Society. Standards for the diagnosis and care of patients with chronic obstructive pulmonary disease. Am J Respir Crit Care Med. 1995; 152: 77-121.

28. Xu X, Weiss ST, Rijcken B, et al. Smoking, changes in smoking habits, and rate of decline in FEV1: new insight into gender defferences. Eur Respir J 1994; 7: 1056-61.

29. Lipton R, Banerjee A. The geography of chronic obstructive pulmonary disease across time: California in 1993 and 1999. Int J Med Sci. 2007; 4: 179-89.

30. Thorn J, Björkelund C, Bengtsson C, et al. Low socio-economic status, smoking, mental stress and obesity predict obstructive symptoms in 
women, but only smoking also predicts subsequent experience of poor health. Int J Med Sci 2007; 4: 7-12.

31. Rabe KF, Hurd S, Anzueto A, et al. Global strategy for the diagnosis, management, and prevention of chronic obstructive pulmonary disease: GOLD executive summary. Am J Respir Crit Care Med. 2007; 176: 532-55. 